\title{
Using SeaDataNet Management System to preserve the XBT Data-Set of the Mediterranean Sea
}

\author{
Pecci Leda ${ }^{1}$, Ciuffardi Tiziana ${ }^{1}$, Reseghetti Franco ${ }^{1}$, Fichaut Michele ${ }^{2}$, Picco Paola ${ }^{3}$, Schaap Dick ${ }^{4}$ \\ ${ }^{1}$ UTMAR, ENEA, Marine Environm Res Ctr, Pozzuolo Di Lerici, SP, Italy. \\ ${ }^{2}$ IFREMER, French Res Inst Exploitat sea, Plouzane, France. \\ ${ }^{3}$ Italian Navy Hydrog Inst, Genoa, Italy. \\ ${ }^{4}$ MARIS, Marine Informat Serv, Voorburg, Netherlands.
}

\begin{abstract}
:
significant amount of Expendable Bathythermograph (XBT) data has been collected in the Mediterranean Sea since 1999 in the framework of operational oceanography activities. The management and storage of such a volume of data poses significant challenges and opportunities. The SeaDataNet project, a pan-European infrastructure for marine data diffusion, provides a convenient way to avoid dispersion of these temperature vertical profiles and to facilitate access to a wider public. The XBT data flow, along with the recent improvements in the quality check procedures and the consistence of the available historical data set are described. The main features of SeaDataNet services and the advantage of using this system for long-term data archiving are presented. Finally, focus on the Ligurian Sea is included in order to provide an example of the kind of information and final products devoted to different users can be easily derived from the SeaDataNet web portal.
\end{abstract}

Keywords : SeaDataNet, XBT, Data Management, Operational Oceanography, Mediterranean Sea

\section{Introduction}

Operational oceanography, forecast, Decision Support Systems, analysis and re-analysis in ocean science all need high quality archived data. Operational oceanography has the aim to produce reliable ocean forecasts to meet the needs of a wide user's community. Decision Support Systems, devoted to support a safer marine traffic, the management of the emergencies as well as coastal and environmental planning, provide valuable results only when based on reliable forecasts. Good forecasts rely on a good observation system. Tremendous efforts have been made in the last years to design and implement operative observational ocean networks. Data quality is essential but also a complete set of metadata, an efficient management and an accurate and quick storage system are fundamental. For a scientist, a construction engineer or a policy maker, the development of a good observation and data management system is the only tool he can rely on to save time and effort looking for data. The SeaDataNet infrastructure is a model for other platforms devoted to marine data management. 
In this paper, we describe the SeaDataNet system, a storage and management system specifically addressed to the management of ocean data and information. The paper will focus on the management of Expendable Bathythermograph (XBT) data collected in the Mediterranean. 
Different instruments can supply oceanographic information but among the components of an integrated marine observatory. XBTs represent one of the main tools to provide a wide coverage of relevant ocean observations at a basin scale and account for the majority of available archived recent data. XBT is an oceanographic instrument to measure the temperature of the water column. These probes were initially developed for military application to provide a rapid assessment of the sound speed profiles in the area of the operations, as they have the advantage of being deployed from moving ships. For this reason XBTs have been also successfully adopted by oceanographers to collect temperature profiles from commercial ships (Ship Of Opportunity Programs-SOOP). XBT profiles constituted the major portion of ocean subsurface temperature observations during the late 1960s through the early 2000s, with more than 18\% of upper ocean temperature profiles in the World Ocean Database 2013 ([1]). Currently, approximately 20000 XBTs are deployed worldwide every year mostly along fixed transects and in high-density mode, where each transect is repeated approximately 4 times per year and the deployments are carried out every $20-30 \mathrm{~km}$. This has made XBTs indispensable for studying historical ocean heat content changes in the upper ocean, making the instrument a key tool in numerous scientific investigations such as climatic and impact assessment, marine strategy and model validation. Nevertheless XBTs were not designed for the accuracy needed for climate studies and have been shown to possess a time-varying bias in both depth and temperature. Accurate correction of this bias is important for proper use of the XBT data but there is no general consensus among researchers about the best correction scheme ([2], [3], [4]).

\section{The XBT MediterRanean Database through SeaDataNet}

In September 1999, a SOOP was established in the Mediterranean Sea on behalf of the European funded project MFS Pilot Project (MFS-PP, [5]), followed by an improved version during MFS Toward Environmental Prediction (MFS-TEP, [6]), and maintained as part of the more comprehensive Mediterranean Operational Oceanography Network (MOON). During the earlier part of MFS activities, XBT probes were deployed along six transects crossing the Mediterranean from North to South and one long transect crossing the whole sea from East to West (Fig. 1). These transects were designed to monitor the variability of the main circulation features in each of the sub-basins (the Algero-Provencal, the Tyrrhenian, the south Adriatic, the Ionian and the Levantine).

Budget constraints limited the number and the position of the tracks during the years, shifting the purpose of the Mediterranean SOOP from an operational observing system devoted to providing data for forecasts to a climate variability observing system. Actually, as regards Italy, under the initial coordination of GNOO (National Group of Operational Oceanography), ENEA (Italian National Agency for New Technologies, Energy and Sustainable Economic Development) regularly operates two transects across the Mediterranean Sea, to be covered at a seasonal scale: Genoa-Gibraltar, Genoa-Palermo. In 2013 and 2014 the route between the Strait of Messina and Cape Tainaron has been covered as well at seasonal rate, whereas previously few surveys have been conducted across the Levantine basin. At the end of each data acquisition, temperature profiles are subjected to quality control (QC) procedures specifically developed for Mediterranean seawater.

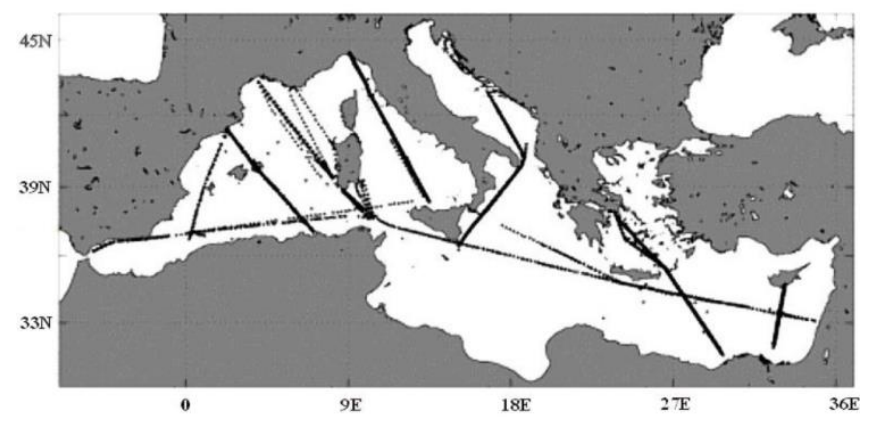

Fig. 1. The approximate position of the seven tracks in MFSPP [7].

A continuous improvement has been achieved starting from the pioneering period (September 1999) and after discussions in the XBT scientific community, QC was based on Medar-Medatlas protocols ([9]), and included all the steps of the delayed mode, with the addition of a visual check at the beginning and at the end of the procedure ([7]). In detail, the steps are the following:

- detection of the end of the profile and gross range check;

- position control;

- elimination of spikes;

- Gaussian smoothing and re-sampling at 1-m interval;

- general malfunction control;

- comparison with climatology and final visual check.

After this: 
- the first $4 \mathrm{~m}$ were eliminated;

- the interval $10^{\circ} \mathrm{C}-30^{\circ} \mathrm{C}$ was selected as range of acceptable temperature;

- the maximum temperature inversion was fixed at $4.5^{\circ} \mathrm{C}$ in the upper $200 \mathrm{~m}$, and $1.5^{\circ} \mathrm{C}$ below $200 \mathrm{~m}$ depth;

- the accepted maximum temperature gradient was $3^{\circ} \mathrm{C} / \mathrm{m}$.

Data collection and QC procedures were organized to deliver data with a relatively short time delay (no more than about $24 \mathrm{~h}$ after the data taking), and timely for the weekly data assimilation process.

\section{THE SEADATANET PROJECT AS A BOX FOR XBT DATA}

Considering the available historic XBT information great importance has a safe and easy system for their management and diffusion. The SeaDataNet project is a answer to avoid the dispersion of these valuable data and to facilitate the access to a wider public.

The SeaDataNet project was funded by EU and operated from 2006 until 2010. The activity is still ongoing in SeaDataNet II (2011-2015), an EU project funded by FP7 (Seventh Framework Programme for Research) ) [10]. The project has developed an efficiently distributed marine data management infrastructure, offering, throughout a single site, an overview of marine organisations, data collections, monitoring and research activities related to the sea. Overall 44 institutions, active in data collection, are involved as project partners and 10 institutions as associate partners, representing 35 countries: they constitute a pan-European infrastructure for marine data diffusion supporting scientific activities related to the different aspects of the marine environment such as climate, physical oceanography, fishery, chemistry, geology, geophysics and biology.

In order to allow an effective data exchange is not sufficient to build an Information Technology (IT) infrastructure connecting distributed data repositories. "Data curation" is also needed to maintain, preserve and add value to digital research data throughout its lifecycle [11]. SeaDataNet embraces that policy, typical of the quality data management, defining best practices, procedures and implementing tools to ease the data sharing from heterogeneous sources. To this purpose, some common vocabularies have been developed and adopted [12], each one specialised for a specific discipline. In the framework of SeaDataNet, ad hoc applications have been implemented in order to produce metadata and to convert the data format to the same standards. This contributes to interoperability, effectively sharing reliable data across scientific domains and international boundaries. A common information model for data and metadata has been defined along with quality check procedures. The software procedures are well documented and the data managers have received training courses.

The project through its web portal offers many different services for data and metadata, including: discovery and data access service and also data products.

\section{Metadata services:}

They let the user to have an overview of the marine organisations in Europe, their participation in marine research projects, the large managed datasets, the current and historical data collected by research vessels and monitoring programmes for the European seas and global oceans.

\section{Data services:}

The SeaDataNet portal offers different services: discovering, visualization, access and data downloading.

SeaDataNet combines together many different instruments to pool, share and distribute marine data in an interoperable way.

Thanks to Common Data Index (CDI), it is possible to select an area, discover and download all the data available, as shown in Fig. 2. It provides a way for downloading data residing in distributed nodes, in compliance to the Infrastructure for Spatial Information in the European Community (INSPIRE) directive [13]. Only the data discovery doesn't require any registration. Any user, after registering for free, may have access to data, the major part of them (85\%) being freely available. The remaining $15 \%$ data have access restrictions and the user has to make arrangements with the data provider to negotiate access for the downloading. 


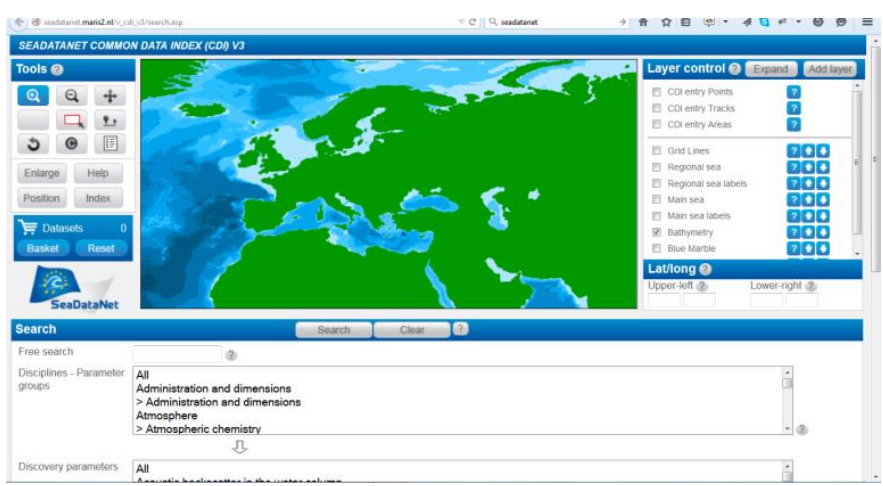

Fig. 2. Common Data Index interface from SeaDataNet webpage [10].

Data products: SeaDataNet prepares and publishes basic products as aggregated sets of observation data, model data, images. The products are available on line together with specialised browsing, visualisation, and downloading services.

\section{Providing COMPILED PRoducts: The CASE OF THE Ligurian SEA Climatology}

A considerable amount of formatted, structured and well organised XBT data collected in the Mediterranean Sea are available. The total number of Mediterranean XBT profiles in the SeaDataNet system and the geographical distribution is shown in (Fig. 3).

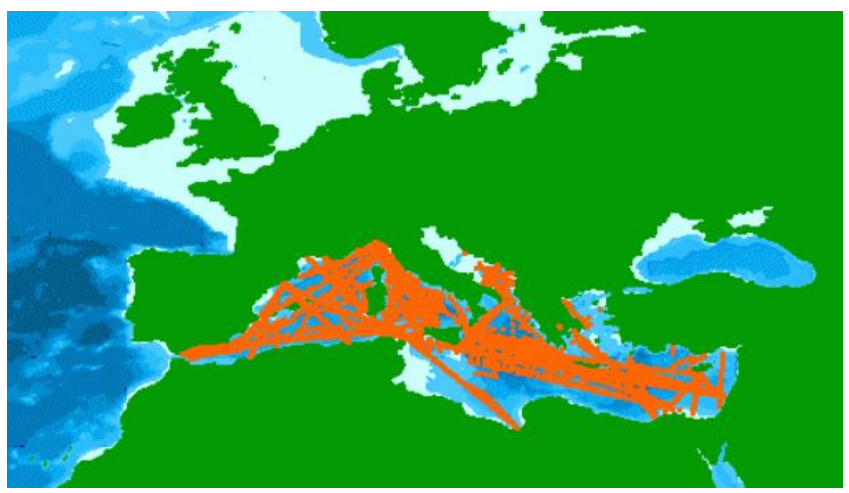

Fig. 3. Distribution of XBT data casts for Operational Oceanography in the Mediterranean Sea.

An example of how SeaDataNet facilitates the production of compiled products, such as seasonal temperature maps is here described.

Data from Ligurian Sea have been selected, in order to provide information on temporal and spatial variability easily derivable from the SeaDataNet web portal. The water temperature observations in this portion of the Mediterranean basin mainly consist of the profiles collected along the Genoa-Palermo route and cover the years from 1999 to 2014 (Fig. 4a) with a vertical resolution of $1 \mathrm{~m}$ during 64 different oceanographic surveys. Detailed monthly distribution is presented in Fig. 4b.

(a)

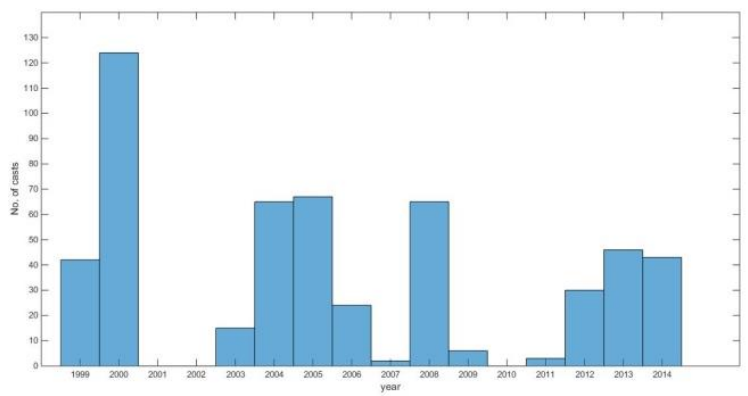

(b) 


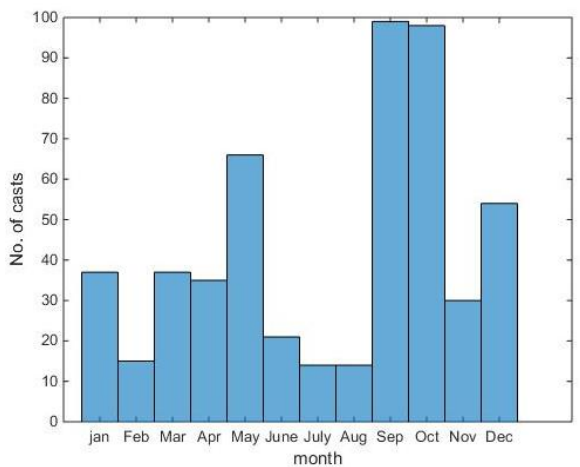

Fig. 4. Annual (a) and monthly (b) distribution of XBT data measured in the Ligurian Sea from 1999 to 2014 from SeaDataNet website.

The total number of casts is 520, but the majority of observations are carried out along the track from Genoa to Capraia (Fig. 3 ). The requirements on spatial sampling were constrained by the internal Rossby radius, which varies from 5 to $20 \mathrm{~km}$ in the Mediterranean, whereas the temporal sampling was dependent on mesoscale time scales. The optimal time sampling interval in the Mediterranean was defined to be about one week ([14]). This high density sampling strategy could not be adopted for many practical reasons, the lack of human and economical resources being the most important. In practice, the sampling scheme was adapted every time to the ships and resources available: the lower amount of data available in summer, due to tourism flows that prevent the use of passengers ships for the monitoring activity, clearly reflects this constraint (Fig. 5).

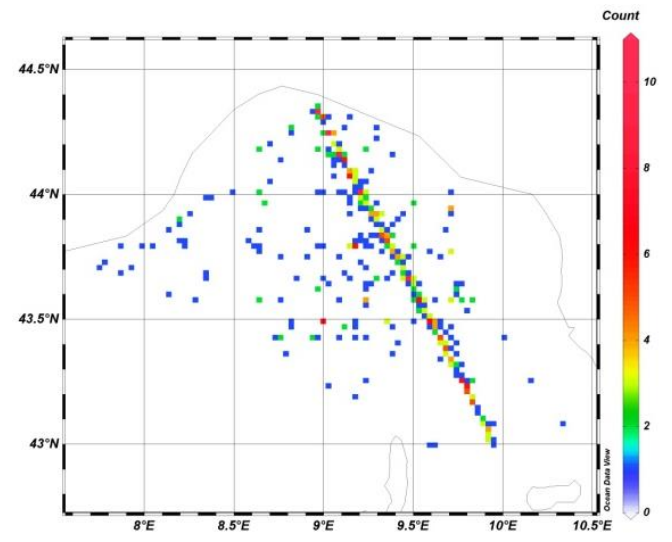

Fig. 5. Distribution of XBT profiles in the Ligurian Sea available from SeaDataNet website

To obtain a general view of the temperature structure, the main Genoa-Capraia route was analysed during two different periods (March and September). The difference between the temperature structures is clearly shown in Fig. 6 and Fig. 7, where the temperature profile across the section is shown for September and March respectively.

The seasonal evolution of the upper layer shows the late summer stratification and winter mixing: temperature profiles collected in September describe a two layer system where the water column is strongly stratified, with marked thermocline that isolate the surface water from the deeper water masses.

The thermocline is located around 60-70 $\mathrm{m}$ depth, whereas the upper 70-80 m layer is quite well stratified with water temperature ranging between 15 and $24^{\circ} \mathrm{C}$. The summer thermocline disappears around November or early December, when the strong vertical mixing homogenizes the water column, with a progressive cooling of the upper layer until March (Fig. 8). 
(a)

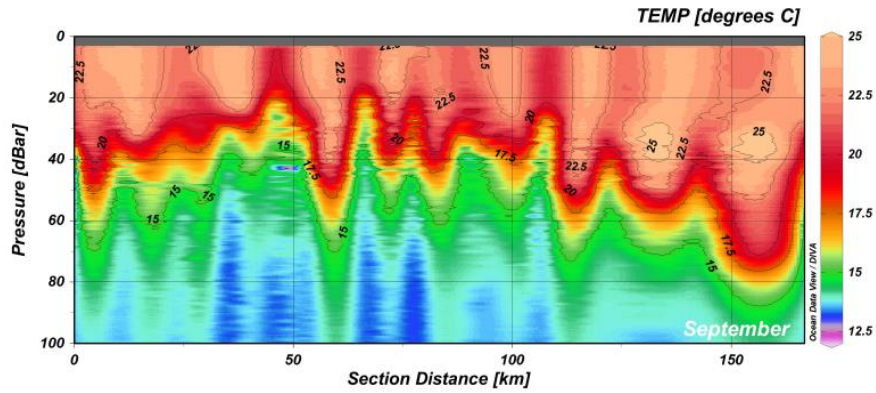

(b)

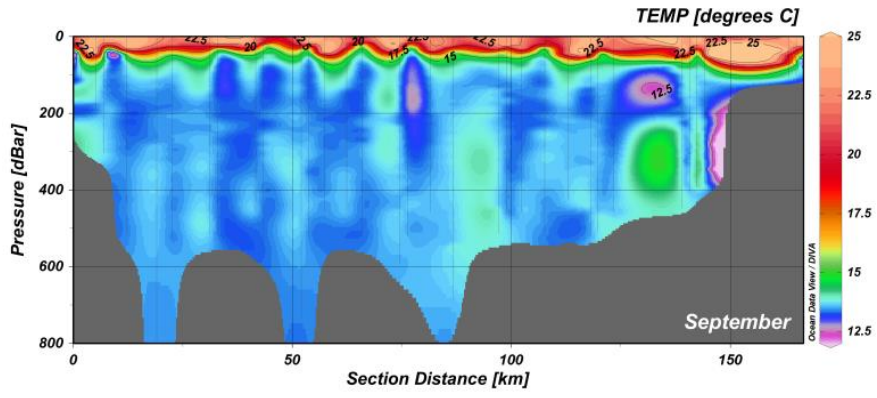

Fig. 6. Temperature section during September from Genova to Capraia ((a), the upper 100 metres, (b) the data from surface down to the maximum depth).

(a)

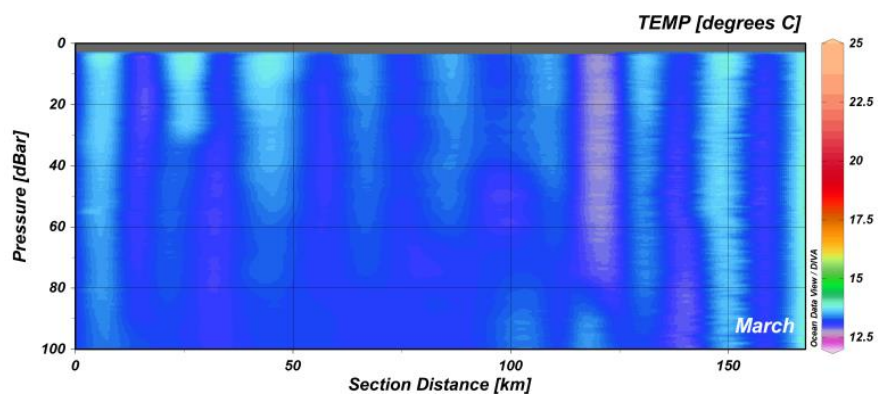

(b)

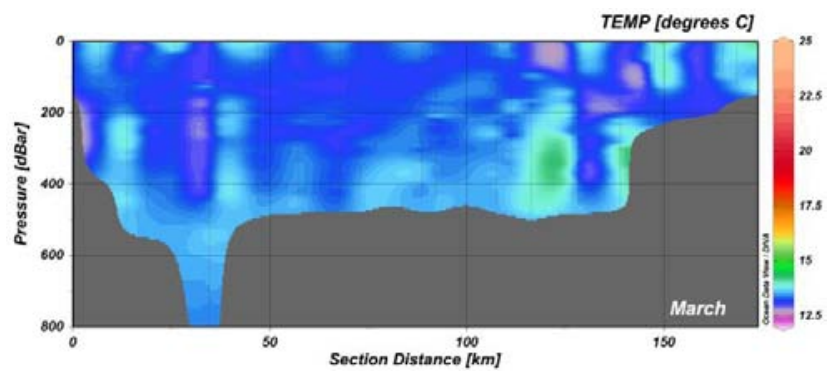

Fig. 7. Temperature section during March from Genova to Capraia ((a), the upper 100 metres, (b) the data from surface down to the maximum depth).
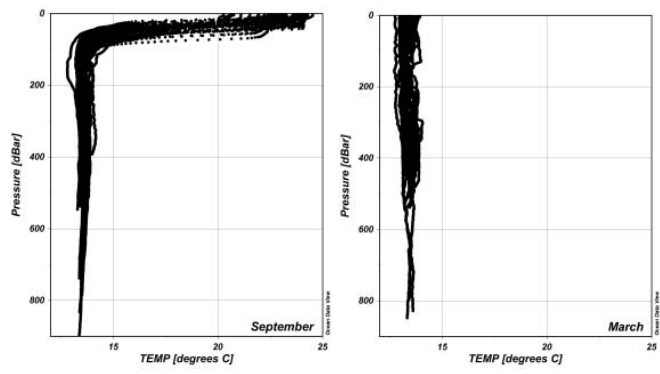

Fig. 8. Temperature data distribution along the vertical from Genova to Capraia (September vs. March) 


\section{CONCLUSIONS}

All marine data are unique and precious. Even if collected to respond to specific requirements (rapid assessment, operational oceanography, scientific investigation or environmental quality control), in the future they may result in becoming of crucial importance in different unpredictable applications. The main example is the case of the climatic studies which rely on the existence of preserved historical data. Due to the development of new marine technologies and to the diffusion of environmental monitoring networks, the amount of marine data has increased exponentially. As the scientific community faces the problem of how to preserve this valuable data for the future and how to make the data and information easily available to a wider range of users, different programmes on data management have been set up. SeaDataNet is the result of the joint efforts of several marine institutes around the European and the Mediterranean seas. The objective of this network is to provide an archiving system for quality checked marine environment data, to strongly contribute to the definition of standards aimed at assuring the interoperability among different data sources and to promote the data submission from data providers. The main result of the project is the significant amount of marine data submitted by different institutions, which is now available for the public. Another reached achievement of SeaDataNet is the building of a collaborative community, through the participation of computer science experts, specialised technicians, oceanographers, marine researchers, scientists and data managers. Many institutions throughout Europe have been cooperating for data and information exchanging, metadata and data standards definition. Over the last nine years the SeaDataNet consortium partners have been working together, generating a strong sense of trust and ownership.

Finally, the technologies and standards developed in the project have been adopted by the following European projects: Black Sea Scene, CASPINFO (Caspian environmental and industrial data \& information service), EMODnet (The European Marine Observation and Data Network) for the thematics Bathymetry, Chemistry, Geology and Biology. Interoperability with other data portal like GEOSS (Global Earth Observation System of Systems) and IODE-ODP (International Oceanographic Data and Information Exchange -Ocean Data Portal) has also been developed in the frame of SeaDataNet project.

\section{ACKNOWLEDGMENT}

This work has been supported by SeaDataNet FP7 EU project Contract n 283607.

\section{REFERENCES}

[1] T.P. Boyer et al.,"World Ocean Database 2013”. Sydney Levitus, Ed.; Alexey Mishonov, Technical Ed.; NOAA Atlas NESDIS 72, 209 pp., 2013.

[2] Gouretski, V.V., and Koltermann, K.P., 2007. How much is the Ocean really warming? Geophysical Research Letters 34, L01610, doi:10.1029/2006GL027834.

[3] Abraham, J. P., and Coauthors, 2013: A Review of Global Ocean Temperature Observations: Implications for Ocean Heat Content Estimates and Climate Change. Rev Geophys, 51, 450-483.

[4] Cowley, R., S. Wijffels, L. Cheng, T. Boyer, and S. Kizu, 2013: Biases in Expendable Bathythermograph Data: A New View Based on Historical Side-bySide Comparisons. J. Atmos. Oceanic Technol., 30, 1195-1225.

[5] N. Pinardi, I. Allen, E. Demirov, P. DeMey, G. Korres, A. Lascaratos, P.Y. LeTraon, C. Maillard, C., G.M.R. Manzella, C. Tziavos "The Mediterranean ocean Forecasting System: first phase of implementation (1998 - 2001)", Annales Geophysicae, 21, pp. 3-20, 2003.

[6] G.M.R. Manzella, F. Reseghetti, G. Coppini, M. Borghini, A. Crusado, C. Galli, I. Gertman, D. Hayes, C. Millot, E. Ozsoy, C. Tziavos, Z. Velasquez, G. Zodiatis, "The improvements of the Ships Of Opportunity Program in MFSTEP", Ocean Science, 3, pp. 245-258, 2007.

[7] G.M.R. Manzella, E. Scoccimarro, N. Pinardi and M. Tonani, "Improved near real-time data management procedure for the Mediterranean ocean forecasting system-Voluntary observing ship program", Annales Geophysicae, 21, pp. 49-62, 2003.

[8] F. Reseghetti, M. Borghini and G. M. R. Manzella, "Factors affecting the quality of XBT data-Results of analyses on profiles from the Western Mediterranean Sea", Ocean Sci., 3, pp. 59-75, 2007.

[9] C. Maillard and M. Fichaut, "MEDAR-MEDATLAS Protocol. Part I. Exchange format and quality checks for observed profiles", Rap. Int. TMSI/IDM/SISMER/SIS00-084, pp. 1-49, 2001

[10] http://www.seadatanet.org/

[11] http://www.dcc.ac.uk/

[12] http://www.bodc.ac.uk/products/web_services/vocab/

[13] http://inspire.ec.europa.eu/

[14] F. Raicich,”The assessment of temperature and salinity sampling strategies in the Mediterranean Sea: idealized and real cases”. Ocean Sci., 2, pp. 97-112, 2006. 